J. Lake Sci. (湖泊科学), 2015, 27(1): 113-118

http://www. jlakes. org. E-mail : jlakes@niglas.ac.cn

(C) 2015 by Journal of Lake Sciences

\title{
河蟹养殖池塘微囊藻水华毒性及其光合作用活性特征”
}

李大命 ${ }^{1,2}$, 周 军 ${ }^{1}$, 唐晟凯 ${ }^{1}$, 李旭光 ${ }^{1}$, 林 海 $^{1}$, 张形晴 ${ }^{1}$, 周 刚 $^{1}$

(1: 江苏省淡水水产研究所, 江苏省内陆水域渔业资源重点实验室, 南京 210017)

(2: 中国科学院南京地理与湖泊研究所湖泊与环境国家重点实验室,南京 210008)

摘 要: 苏州市吴中区一河蟹养殖池塘在 2013 年 7 月和 8 月发生了严重的微囊藻水华. 采用单一和双重 PCR 扩增微囊 藻毒素合成酶基因, 用以检测微囊藻水华是否产毒, 结果显示为阳性. 同时, 采用高效液相色谱测定微囊藻水华的毒性大 小. 结果表明:7 月和 8 月微囊藻水华的胞内微囊藻毒素浓度分别为 1.49 和 $0.88 \mu \mathrm{g} / \mathrm{L}$, 胞外微囊藻毒素的浓度分别为 0.75 和 $1.09 \mu \mathrm{g} / \mathrm{L}$. 另外, 采用浮游植物苂光仪 Phyto-PAM 测定河蟹养殖水体形成水华的微囊藻的光合作用活性. 结果显 示: 7 月和 8 月水华微囊藻的最大光量子产量 $F_{\mathrm{v}} / F_{\mathrm{m}}$ 分别为 0.48 和 0.44 , 实际光量子产量 $\Phi_{\mathrm{PSII}}$ 分别为 0.38 和 0.32 , 表明 形成水华的微囊藻有较高的生长潜力. 非光化学苂光淬灭值 $N P Q$ 分别为 0.28 和 0.36 . 从快速光响应曲线 RLC 的特征参 数来看, 7 月水华微囊藻的光合作用活性和光能利用效率高于 8 月. 本研究结果表明, 河蟹养殖池塘水体受到微囊藻水华 和微囊藻毒素的污染, 进而可能对河蟹食品安全构成潜在威胁.

关键词: 河蟹养殖池塘; 微囊藻水华; 微囊藻毒素; 微囊藻光合作用活性; 浮游植物荧光仪

\section{Toxicity and photochemical activity of Microcystis bloom in crab cultivation pond}

LI Daming ${ }^{1,2}$, ZHOU Jun ${ }^{1}$, TANG Shengkai ${ }^{1}$, LI Xuguang ${ }^{1}$, LIN Hai ${ }^{1}$, ZHANG Tongqing ${ }^{1}$ \& ZHOU Gang ${ }^{1}$ (1: Key Laboratory of Fisheries Resources in Inland Water, Freshwater Fisheries Research Institute of Jiangsu Province, Nanjing 210017 , P. R. China)

(2: State Key Laboratory of Lake Science and Environment, Nanjing Institute of Geography and Limnology, Chinese Academy of Sciences, Nanjing 210008, P. R. China)

Abstract: In July and August of 2013, Microcystis bloom occurred in a crab pond which was located in Wuzhong district, the city of Suzhou. In the present study, single and double PCR amplification for microcystin synthetase gene were used to detect whether the Microcystis bloom was toxigenic or not. All PCR products from Microcystis bloom materials were positive. Meanwhile, high performance liquid chromatography technique were used to measure the microcystin concentration of Microcystis bloom, the results showed that intracellular microcystin concentration were 1.49 and $0.88 \mu \mathrm{g} / \mathrm{L}$ in July and August, and intracellular microcystin concentration were 0.75 and $1.09 \mu \mathrm{g} / \mathrm{L}$, respectively. In addition, Phyto-PAM was applied to measure photochemical activity of bloom-forming Microcystis. The value of maximum quantum yield $F_{\mathrm{v}} / F_{\mathrm{m}}$ were 0.48 and 0.44 in July and August, and the effective quantum yield $\Phi_{\mathrm{PSII}}$ were 0.38 and 0.32 , respectively. These results suggested that bloom-forming Microcystis had higher potential growth, and the value of non-photochemical quenching were 0.28 and 0.36 . From the view of characteristical parameters of rapid light response light curve, it demonstrated that the photochemical activity of bloom-forming Microcystis in July is higher than that in August. The experiment results from this study suggested that water in crab culture pond has suffered from Microcystis bloom and microcystin contamination may present potential threat to crab food safety.

Keywords: Crab pond; Microcystis bloom; microcystin; photochemical activity; Phyto-PAM phytoplankton analyzer

蓝藻水华在富营养化的湖泊、水库和养殖池塘中频繁发生已成为当前水环境面临的重大问题. 蓝藻水 华能产生多种具有毒性效应的蓝藻毒素 (Cyanotoxins), 对水生态系统结构和功能、社会经济发展和人类健康

* 江苏省青年科学基金项目 (BK2012488) 和国家 “十二五” 子课题河蟹池塘高效生态养殖技术集成与示范项目 (2012BAD25B07) 联合资助. 2013-12-20 收稿;2014-04-14 收修改稿. 李大命 (1981～), 男, 博士, 助理研究员; E-mail:1dm8212@126.com. 
都造成了严重的影响. 微囊藻是形成蓝藻水华最常见的优势种类, 微囊藻水华分布范围广, 持续时间长, 发 生频率高, 且微囊藻能合成产生一系列具有肝毒性效应的微囊藻毒素 (Microcystin, MC), 它们能够抑制肝细 胞中的蛋白磷酸酶活性 ${ }^{[1]}$. 长期饮用含有 $\mathrm{MC}$ 的水, 可能引发肝癌 ${ }^{[2]}$. 世界卫生组织 ( WHO) 建议饮用水源中 $\mathrm{MC}$ 的安全浓度阈值 $<1.0 \mu \mathrm{g} / \mathrm{L}$, 水产品中每日人体可允许摄人的 $\mathrm{MC}<0.04 \mu \mathrm{g} / \mathrm{kg}^{[3]}$.

$\mathrm{MC}$ 是一种小分子环状多肽, 结构稳定. 研究表明, MC 是由微囊藻毒素合成酶基因家族 (microcystin synthesis gene, $m c y)$ 编码的多酶复合体催化合成. 应用分子生物技术已经阐明了 $m c y$ 基因家族结构,并完成了 序列分析. $m c y$ 基因家族是由两个反方向的操纵子组成, 包含 10 个家庭成员 $(m c y \mathrm{~A}-\mathrm{J})^{[4-5]}$. 文献报道微囊藻 细胞中是否含有 $m c y$ 基因与微囊藻毒素产生有密切相关性 ${ }^{[6]}$. 基于此, 设计了针对 $m c y$ 基因家族成员的引 物, 建立了检测微囊藻水华是否产毒的 PCR 扩增技术, 可以对微囊藻水华是否产毒做出快速和准确判

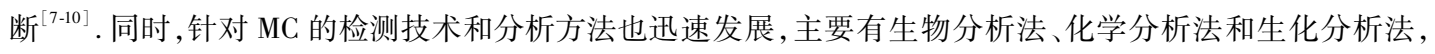
高效液相色谱 (High Performance Liquid Chromatography, HPLC) 是目前应用、研究最多的方法 ${ }^{[1]}$.

近 10 多年来, 我国河蟹养殖业有了迅猛的发展, 养殖技术有了很大提高, 池塘养殖密度不断增大, 对水 体的投人也在增加, 造成养殖池塘水体富营养化和环境恶化, 导致河蟹养殖池塘蓝藻水华频繁发生, 对河蟹 养殖造成巨大损失. 已有一些文献对于养殖池塘蓝藻水华现象进行了报道, 但对于微囊藻水华的毒性大小 和微囊藻的生理特征尚缺乏研究. 2013 年 7 月和 8 月, 苏州市吴中区一河蟹池塘发生了严重的微囊藻水华, 显微镜检测结果表明铜绿微囊藻是其水华的优势种群. 本研究采用全细胞 PCR 扩增快速检测微囊藻水华是 否有毒, 进一步应用 HPLC 分析方法测定了 MC 浓度. 另外, 应用 Phyto-PAM 苂光仪测定了微囊藻水华的光 合作用活性, 用于研究微囊藻的生理特征. 本研究为了解河蟹养殖池塘微囊藻水华毒性和生理特征提供基 础数据, 同时为评价河蟹食品安全提供科学依据.

\section{1 材料和方法}

\section{1 水样采集}

2013 年 7 月和 8 月苏州吴中区一河蟹养殖池塘发生严重的微囊藻水华, 分别于 7 月 24 日和 8 月 23 日 上午 $10: 00$ 采集水样,使用有机玻璃采水器采集 $10 \mathrm{~L}$ 水样 $(30 \mathrm{~cm})$, 混合均匀, 取 $1 \mathrm{~L}$ 水样装人干净玻璃瓶 中, 每个水样取 2 个平行, 带回实验室进行分析.

\section{2 理化因子测定}

采用哈希水质监测仪 (HQ-40, HACH) 原位测定采样点水体的温度、溶解氧和 $\mathrm{pH}$. 采用透明度盘测定水 体的透明度. 总氮采用碱性过硫酸钾消解一紫外分光光度法测定, 总磷采用钿酸铵分光光度法测定, 叶绿素 a 采用 $90 \%$ 丙酮萃取, 分光光度法测定 ${ }^{[12]}$.

\section{$1.3 m c y$ 基因片段的扩增和检测}

取 $5.0 \mathrm{ml}$ 水样, 10000 转 $/ \mathrm{mim}$ 离心 $10 \mathrm{~min}$ 收集微囊藻细胞, 用超纯水洗涤, 反复 3 次, 最后用 $100 \mu \mathrm{l}$ 超 纯水定容, 置于 $-20^{\circ} \mathrm{C}$ 保存, 作为 PCR 扩增模板.

本研究选择 $m c y \mathrm{~A} 、 m c y \mathrm{D}$ 和 $m c y \mathrm{G}$ 基因作为 $\mathrm{PCR}$ 扩增对象, $\mathrm{PCR}$ 扩增所用引物见表 1. 其中对 $m c y \mathrm{~A}$ 基因 采用单一 PCR 扩增, $m c y \mathrm{D}$ 和 $m c y \mathrm{G}$ 采用双重 PCR 扩增.

表 1 PCR 扩增引物

Tab. 1 Primers used for PCR amplification

\begin{tabular}{llc}
\hline 扩增基因 & 引物序列 & 序列长度/bp \\
\hline \multirow{2}{*}{$m c y \mathrm{~A}^{[9]}$} & $\mathrm{F}: 5^{\prime}$-AAAATTAAAAGCCGTATCAAA-3' & 291 \\
& $\mathrm{R}: 5^{\prime}$-AAAAGTGTTTTATTAGCGGCTCAT-3' & \\
& $\mathrm{F}: 5^{\prime}$-GACGCTCAAATGATGAAAC-3' & 647 \\
& $\mathrm{R}: 5^{\prime}$-GCAACCGATAAAAACTCCC-3' & \\
& $\mathrm{F}: 5^{\prime}$-ACTCTCAAGTTATCCTCCCTC-3' & 425 \\
& $\mathrm{R}: 5^{\prime}$ - AATCGCTAAAACGCCACC-3' & \\
\hline
\end{tabular}


扩增条件: PCR 反应体系 $25 \mu \mathrm{l}$, 其中包含 $12.5 \mu \mathrm{l}, 2 \times \mathrm{PCR} \operatorname{mix}$ (上海博彩生物), $1 \mu \mathrm{l}$ 正反引物 (10 $\mu \mathrm{mol}), 4 \mu \mathrm{l}$ 模板,用超纯水补足 $25 \mu \mathrm{l}$,阴性对照使用超纯水作为 DNA 模板.

反应程序: 预变性 $95^{\circ} \mathrm{C} 5 \mathrm{~min}$, 变性 $95^{\circ} \mathrm{C} 40 \mathrm{~s}$, 引物退火 $58^{\circ} \mathrm{C} 40 \mathrm{~s}(m c y \mathrm{~A})$ 和 $56^{\circ} \mathrm{C} 40 \mathrm{~s}(m c y \mathrm{D}$ 和 $m c y \mathrm{G})$, 延伸 $72^{\circ} \mathrm{C} 40 \mathrm{~s}, 30$ 个循环, 最后在 $72^{\circ} \mathrm{C}$ 下保留 $8 \mathrm{~min}$. 取 $5 \mu \mathrm{l} \mathrm{PCR}$ 产物, 采用浓度 $1.5 \%$ 的琼脂糖凝胶进行电 泳, 缓冲液是 $0.5 \times \mathrm{TAE}$, 电泳结束后在紫外凝胶成像系统中观察、拍照.

\section{4 微囊藻毒素浓度}

取 $200 \mathrm{ml}$ 水样,经 GF/C 玻璃纤维滤膜过滤, 滤膜和滤液分别用于测定胞内和胞外微囊藻毒素的浓 度. 将滤膜置于低温冷冻干燥机中冻干, 剪碎滤膜, 分别用 $5 \%$ 的乙酸溶液和 $80 \%$ 的甲醇溶液各 $5 \mathrm{ml}$ 进行 抽提 ${ }^{[13]}$, 辅以超声波破碎,并充分震荡混匀,离心后合并上清液. 采用 $\mathrm{C}_{18}$ 固相萃取小柱富集和纯化滤膜提 取液和滤液, 用含 $0.1 \% \mathrm{TFA}$ 的甲醇溶液洗脱, 洗脱液在 $40^{\circ} \mathrm{C}$ 氮气吹干, $0.5 \mathrm{ml} 50 \%$ 的甲醇溶液定容 待测.

采用带有紫外检测器的安捷伦高效液相色谱仪 (Agilent1200, Agilent, USA) 进行分析, 检测条件为: 流 动相为含 $0.05 \% \mathrm{TFA}$ 的乙腈溶液, 梯度从 $30 \% \sim 70 \%$, 柱温 $40^{\circ} \mathrm{C}$, 流速 $1 \mathrm{ml} / \mathrm{min}$, 紫外检测器波长为 $238 \mathrm{~nm}$.

\section{5 光合作用活性分析}

采用浮游植物苂光仪 Phyto-PAM (Walz, Effeltrich, German) 测定微囊藻的光合作用活性, 分析软件为 Phyto-WIN v 2.13 , 校零采用 $0.22 \mu \mathrm{m}$ 滤膜过滤水样. 参照文献 [14-15]测定水华微囊藻叶绿素苂光参数. 取 水样 $3.0 \mathrm{ml}$, 暗适应 $15 \mathrm{~min}$. 首先打开光密度很弱的测量光 MR (Measuring light), 仪器检测到最小苂光值 $F_{\mathrm{o}}$, 随后打开饱和脉冲 (Saturation pulse), 得到最大荧光值 $F_{\mathrm{m}}$, 同时, 在光照适应条件下测定其实际最大苂光 值 $F_{\mathrm{m}}{ }_{\mathrm{m}}$ 和实际光合作用效率 $\Phi_{\mathrm{PSII}}$. 设定仪器每隔 $20 \mathrm{~s}$ 加以逐渐增强光化光 (active light) $\left(16 \sim 764 \mu \mathrm{mol} /\left(\mathrm{s} \cdot \mathrm{m}^{2}\right)\right.$, 同时记录光量子产量, 则得到快速光响应曲线 (Rapid light response curve, RLC), 通过此曲线, 可以得到 3 个 RLC 曲线特征参数: 线性区段斜率 $(\alpha)$ 、最大电子传递速率 $\left(r E T R_{\text {max }}\right)$ 和饱和光照强点 $\left(I_{\mathrm{k}}\right)^{[16]}$. 其中 $F_{\mathrm{v}} / F_{\mathrm{m}}=$ $\left(F_{\mathrm{m}}-F_{\mathrm{o}}\right) / F_{\mathrm{m}}, N P Q=\left(F_{\mathrm{m}}-F_{\mathrm{m}}{ }^{\prime}\right) / F_{\mathrm{m}}{ }^{\prime} . F_{\mathrm{v}} / F_{\mathrm{m}}$ 是最大光量子产量, 用于衡量浮游植物的潜在最大光合效 率; $N P Q$ (non-photochemical quenching) 是非光化学苂光淬灭, 表征浮游植物将过剩光能耗散为热的能力, 即 光保护能力 ${ }^{[17]}$.

\section{2 结果和分析}

\section{1 理化因子}

河蟹养殖池塘采样点 7 月和 8 月总氮分别为 1.68 和 $1.05 \mathrm{mg} / \mathrm{L}$, 总磷浓度分别为 258.28 和 $468.52 \mu \mathrm{g} / \mathrm{L}$, 总氮和总磷浓度均超过水体富营养化标准; 叶绿素 a 浓度分别为 74.8 和 $63.8 \mu \mathrm{g} / \mathrm{L}$, 显微镜观察结果表明微 囊藻水华主要是由铜绿微囊藻 (Microcystis aeruginosa) 组成; 水温分别为 28.5 和 $31.5^{\circ} \mathrm{C}$, 有利于微囊藻水华 形成; 透明度较低, 分别为 30 和 $25 \mathrm{~cm}$; 水质呈碱性, $\mathrm{pH}$ 分别为 10.50 和 9.85 ; 溶解氧分别为 8.51 和 $7.82 \mathrm{mg} / \mathrm{L}$.

\subsection{PCR 产物的检测}

PCR 产物的凝胶电泳检测结果可以看出, PCR 产物的特异性高, 没有引物二聚体 (图 1 ). 7 月和 8 月河 蟹养殖池塘的微囊藻水华样品均能扩增出 $m c y \mathrm{~A} 、 m c y \mathrm{D}$ 和 $m c y \mathrm{G}$ 基因片段, 片段大小与目的基因一致, 可以 初步判断,微囊藻水华具有产毒性.

\section{3 微囊藻毒素浓度}

采用 HPLC 分析方法测定河蟹养殖池塘微囊藻水华毒素浓度, 结果如图 2 所示. 共检出 3 种异构体, 异 构体浓度在 7 月和 8 月存在差异: 7 月微囊藻水华胞内毒素浓度大于 8 月,而胞外毒素浓度相反. 7 月微囊 藻水华胞内毒素浓度为 $1.49 \mu \mathrm{g} / \mathrm{L}$, 其中异构体 $\mathrm{RR} 、 \mathrm{YR}$ 和 LR 浓度分别为 $0.46 、 0.45$ 和 $0.58 \mu \mathrm{g} / \mathrm{L}$. 胞外毒 素浓度为 $0.75 \mu \mathrm{g} / \mathrm{L}, \mathrm{RR} 、 \mathrm{YR}$ 和 LR 浓度分别为 $0.22 、 0.18$ 和 $0.35 \mu \mathrm{g} / \mathrm{L} ; 8$ 月胞内微囊藻毒素浓度达 $0.88 \mu \mathrm{g} / \mathrm{L}$, 其中异构体 $\mathrm{RR} 、 Y R$ 和 LR 浓度分别为 $0.27 、 0.31$ 和 $0.30 \mu \mathrm{g} / \mathrm{L}$. 胞外微囊藻毒素浓度为 $1.09 \mu \mathrm{g} / \mathrm{L}, \mathrm{RR} 、 \mathrm{YR}$ 和 LR 浓度分别为 $0.39 、 0.28$ 和 $0.42 \mu \mathrm{g} / \mathrm{L}$.

\section{4 微囊藻光合作用活性}

从水华微囊藻的叶绿素苂光参数可以看出, 7 月和 8 月微囊藻的最大光量子产量 $F_{\mathrm{v}} / F_{\mathrm{m}}$ 分别为 0.48 和 

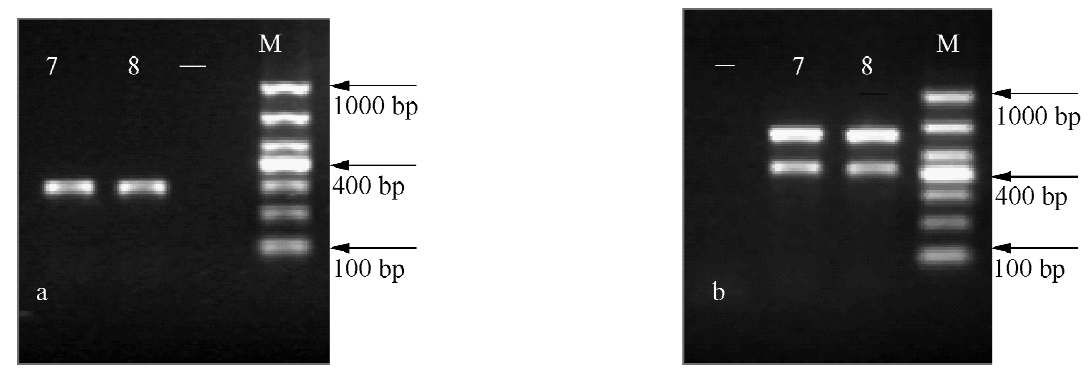

图 1 PCR 产物凝胶电泳图谱 $(\mathrm{M}$ :分子标记,DL1000;7 和 $8:$ 相应月份微囊藻水华样品, 一:阴性对照;左图 a:mcyA PCR 产物,右图 b:mcyD 和 $m c y \mathrm{G}$ PCR 产物)

Fig. 1 Agarose gel electrophoresis images of PCR products( M: Marker, DNA ladder 1000; 7 and 8 indicate the Microcystis bloom samples in July and August, respectively ;-: negative control; (a) : mcy A,(b): mcyD and $m c y \mathrm{G}$ )

四LR 目YR四RR

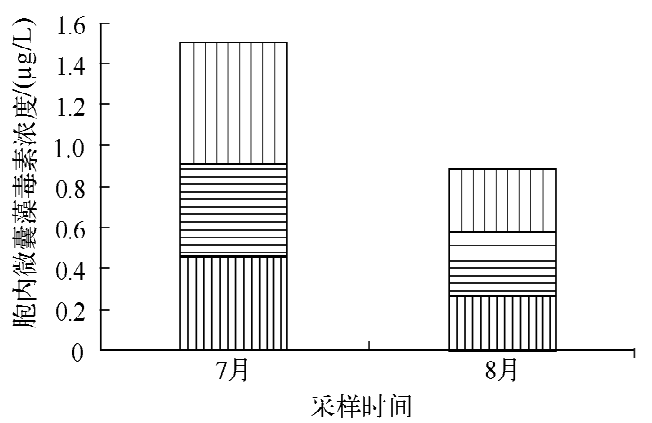

采样时间

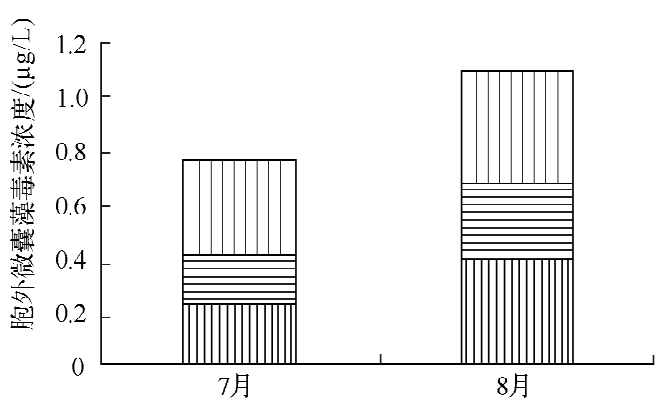

采样时间

图 2 胞内和胞外微囊藻毒素浓度

Fig. 2 Intracelluar and extracellular microcystin concentrations

0.44 , 实际光量子产量 $\Phi_{\mathrm{PSI}}$ 分别为 0.38 和 0.32 (图 3 ), 表明水华期间微囊藻有较高的光合作用活性. 从 $N P Q$ 值可以看出, 8 月微囊藻的热耗散能力高于 7 月. 从光响应曲线的特征参数可以看出, 7 月微囊藻的光 能利用效率、耐受光强能力和电子传递速率均高于 8 月 (图 3).

\section{3 讨论}

河蟹已成为我国淡水渔业养殖的重要品种之一. 近年来, 河蟹池塘养殖技术有很大提高, 放养密度逐渐 加大, 饵料投人不断增加, 导致养殖水体环境恶化, 营养盐负荷增加, 养殖水体变肥, 呈现富营养化状态. 池 塘水体的总氮和总磷浓度均超过富营养化标准, 导致水体透明度也较低, 加之养殖池塘是封闭性水体, 流动 性差. 同时,2013 夏季 7 月和 8 月出现了长时间持续的高温晴朗天气,这些都是促使微囊藻水华发生的有利 条件 ${ }^{[18]}$. 在水华形成时, 水体中叶绿素 $\mathrm{a}$ 的浓度一般在 $10 \mu \mathrm{g} / \mathrm{L}$ 以上. 在该研究中,7、8 月两次采样池塘水体 中微囊藻水华的叶绿素 a 浓度分别达到 74.8 和 $63.5 \mu \mathrm{g} / \mathrm{L}$, 均显著高于 $10 \mu \mathrm{g} / \mathrm{L}$, 表明微囊藻水华强度较 高. 显微镜检测发现, 铜绿微囊藻是微囊藻水华的优势种群.

光合作用活性是指示微囊藻生理特征的重要指标, 目前多采用叶绿素荧光技术测定浮游植物的光合作 用活性. Phyto-PAM 是专一测定浮游植物光合活性的苂光仪, 在研究湖泊微囊藻水华中广泛用来测定水华 微囊藻的光合活性 ${ }^{[19-20]}$. 从本研究结果可以得出 (图 3), 7 月和 8 月水华微囊藻有较高的光合作用活性, 其 最大光量子产量 $F_{\mathrm{v}} / F_{\mathrm{m}}$ 分别为 0.48 和 0.44 , 实际光量子产量 $\Phi_{\mathrm{PSI}}$ 分别为 0.38 和 0.32 , 这表明该河蟹养殖 
池塘形成水华的微囊藻有较高生长潜能, 有利于微囊藻水华 长时间存在. 同时可以得出, 7 月和 8 月形成水华的微囊藻光 合活性存在差异:7 月微囊藻的光合活性高于 8 月. 微囊藻光 响应曲线的特征参数也可以说明这一点. 从水温变化看, 8 月 池塘水体的温度 $\left(31.5^{\circ} \mathrm{C}\right)$ 高于 7 月 $\left(28.5^{\circ} \mathrm{C}\right)$, 研究表明在上 述温度范围内, 温度升高有利于提高微囊藻的光合活 性 ${ }^{[21-22]}$, 但 8 月微囊藻的光合活性反而较低, 可能是由于微 囊藻受到夏季太阳光长时间照射产生光抑制的现象. 已有许 多文献报道微囊澡在夏季强光照射下,光合作用器官受到损 伤, 进而光合作用活性下降 ${ }^{[19-20]}$. 另一方面, 微囊藻可以通过 $N P Q$ 机制降低光损伤 ${ }^{[15]}$, 从本研究结果可以看出, 8 月微囊 藻 $N P Q$ 值高于 7 月微囊藻, 这也是微囊藻在长时间高光强条 件下的一种适应机制.

PCR 检测法是检测微囊藻水华是否产毒的常用方法之 一, 它具有灵敏度高、操作简单、结果准确等优势 ${ }^{[7-8]}$. PCR 扩增对象可以是从水华微囊藻提取的 DNA, 也可以是微囊藻 细胞. 相比较而言, 全细胞 PCR 可以直接以野外微囊藻细胞 为扩增对象,省去了繁琐的 DNA 提取过程,在自然水体蓝藻 水华检测中已有广泛应用 ${ }^{[23]}$. 同时, 从单一 PCR 扩增向双重 和多重 PCR 扩增发展 ${ }^{[8]}$. 本研究采用全细胞的单一和双重 PCR 方法扩增了河蟹养殖池塘水华微囊藻的 $m c y$ 基因,结果 显示为阳性 (图 1), 表明微囊藻水华是产毒的,与 HPLC 分析 结果一致(图 2), 表明该池塘水体受到 MC 污染. 与张占会 等 ${ }^{[8]}$ 建立的全细胞多重 PCR 检测产毒微囊藻方法相比, 本研 究所选用引物特异性高, 目的基因条带清晰, 没有非特异性 产物和引物二聚体出现. 因此, 对于野外微囊藻的全细胞 PCR 扩增而言, 需要选择特异性高的引物, 并对 PCR 反应进 行优化.

从 HPLC 分析结果可以得出, 7 月微囊藻水华胞内、外 $\mathrm{MC}$ 浓度分别为 1.49 和 $0.75 \mu \mathrm{g} / \mathrm{L}, 8$ 月胞内、外 $\mathrm{MC}$ 浓度分 别为 0.88 和 $1.09 \mu \mathrm{g} / \mathrm{L}$, 呈现出季节差异性, 这可能与微囊 藻水华生长阶段有关. 一般而言, 在微囊藻水华生长的前期 和中期, 胞内毒素含量较高, 而胞外毒素浓度较低; 在微囊藻 水华的后期, 微囊藻细胞出现衰亡, 微囊藻毒素释放到水体 中, 微囊藻胞内毒素降低, 胞外毒素升高. 另外, 环境因子 (温 度、光照和营养盐) 的差异也可能是导致 $\mathrm{MC}$ 浓度变化的原 因. 由于 $\mathrm{MC}$ 性质较稳定, 可以在水体中长期存在, 且能通过 食物链进行传递, 在水生动物体内富集, 对鱼类、甲壳类的食 品安全构成潜在威胁, 因此 MC 在可食性水产品中的分布及 其动态变化成为研究热点 ${ }^{[24-28]}$. 本研究结果表明, 河蟹养殖 池塘发生有毒微囊藻水华, 水体受到 MC 污染, 这可能会对 河蟹食品安全构成威胁,需要对河蟹体内 $\mathrm{MC}$ 浓度及其动态 变化做进一步研究.
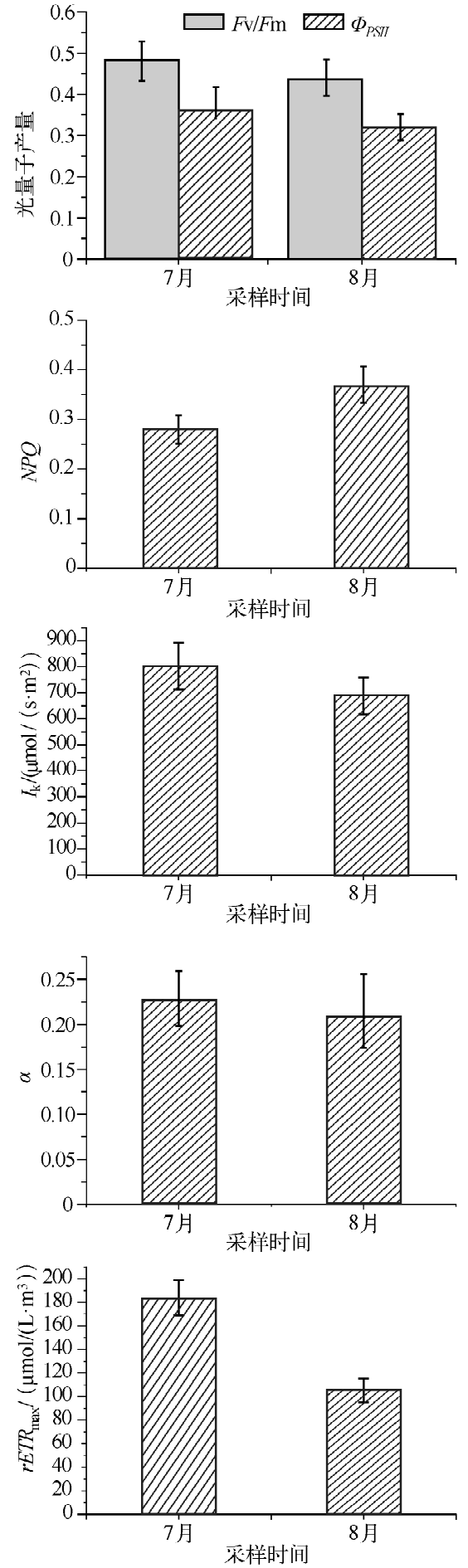

图 3 水华微囊藻的光合作用活性

Fig. 3 Photochemical activity of bloom-forming Microcystis 


\section{4 参考文献}

[ 1 ] Gehringer M. Microcystin-LR and okadaic acid-induced cellular effects : a dualistic response. FEBS Letters, 2003,557 (1/ $2 / 3): 1-8$.

[ 2 ] Svirčev Z, Krstić S, Miladinov-Mikov M et al. Freshwater cyanobacterial blooms and primary liver cancer epidemiological studies in Serbia. Journal of Environmental Science and Health Part C, 2009,27 (1):36-55.

[ 3 ] Chorus I, Bartram J. Toxic cyanobacteria in water: A guide to their public health consequences, monitoring and management. World Health Organization, London/New York: E \& FN Spon Publishers, 1999.

[ 4 ] Nishizawa T, Ueda A, Asayama M et al. Polyketide synthase gene coupled to the peptide synthetase module involved in the biosynthesis of the cyclic heptapeptide microcystin. Journal of Biochemistry, 2000,127(5) : 779-789.

[ 5 ] Tillett D, Dittmann E, Erhard M et al. Structural organization of microcystin biosynthesis in Microcystis aeruginosa PCC 7806: an integrated peptide-polyketide synthetase system. Chemistry Biology, 2002,7(10):753-764.

[ 6 ] Kurmayer R, Dittmann E, Fastner J et al. Diversity of microcystin genes within a population of the toxic cyanobacterium Microcystis spp. in Lake Wannsee(Berlin, Germany). Microbial Ecology, 2002,43(1):107-118.

[ 7 ] 潘 卉,宋立荣,刘永定等. 水华蓝藻产毒特性的 PCR 检测法. 水生生物学报,2001,25(2):159-166.

[ 8 ] 张占会, 谢数涛, 韩博平等. 全细胞多重 PCR 检测蓝藻、微囊藻及产毒微囊藻方法初探. 生态科学, 2005, 24 (1): 31-34.

[ 9 ] Hisbergues M, Christiansen G, Rouhiainen L et al. PCR-based identification of microcystin-producing genotypes of different cyanobacterial genera. Archives of Microbiology, $2003, \mathbf{1 8 0}$ (6) : $402-410$.

[10] Ouahid Y, Pérez-Silva G, Del Campo FF. Identification of potentially toxic environmental Microcystis by individual and multiple PCR amplification of specific microcystin synthetase gene regions. Environment Toxicology, 2005, 20 (3) : 235-242.

[11] 张维吴, 徐小清, 丘昌强. 水环境中微囊藻毒素研究进展. 环境科学研究,2001,14(2):57-61.

[12］黄祥飞. 湖泊生态调查观测与分析. 北京: 中国标准出版社, 1999:77-79.

[13] 彭 亮,陈 伟,宋立荣. 微囊藻胞内毒素的提取方法. 水生生物学报,2011,35(4):708-712.

[14] 吴晓东,孔繁翔,曹焕生等. 越冬浮游植物光合作用活性的原位研究. 湖泊科学, 2007,19(2):139-145.

[15] Zhang M, Shi XL, Yu Y et al. The acclimative changes in photochemistry after colony formation of the cyanobacteria $M i$ crocystis aeruginosa. Journal of Phycology, 2011,47(3):524-532.

[16] 张 曼, 曾 波. PhytoPAM 浮游植物分析仪用于微藻光合作用研究中集中参数设定的优化. 植物生理通讯, 2007, $\mathbf{4 3}(1): 148-152$.

[17] Juneau P, Harrison PJ. Comparison by PAM fluorometry of photosynthetic activity of nine marine phytoplankton grown under identical conditions. Photochemistry and Photobiology, 2005,81 (3) :649-653.

[18 ] O' Neil JM, Davis TW, Burford MA et al. The rise of harmful cyanobacteria blooms: The potential roles of eutrophication and climate change. Harmful Algae, 2012,14:313-334.

[19] Zhang M, Kong FX, Wu XD et al. Different photochemical responses of phytoplankters from the large shallow Taihu Lake of subtropical China in relation to light and mixing. Hydrobiologia, $2008, \mathbf{6 0 3}(1)$ : 267-278.

[20] 李大命, 阳 振, 于 洋等. 太湖春季和秋季蓝藻光合作用活性研究. 环境科学学报,2013,33(11):3053-3059.

[21] Iberlings BW. Changesin photosynthesis in response to combined irradiance and temperatures stress in cyanobacterial surface water blooms. Journal of phycology, 1996,32(4) :549-557.

[22] Christian JR, Coles JF. Effect of temperature on photosynthesis-light resonse and growth of four phytoplankton species isolated from a tidal freshwater river. Journal of Phycology, 2000,36(1) :7-16.

[23] Pan H, Song LR, Liu YD et al. Detection of hepatotoxic Microcystis strains by PCR with intact cells from both culture and environmental samples. Archives of Microbiology, 2002,78(6):421-427.

[24] Magalhães VF, Soares RM, Azevedo SMFO. Microcystin contamination in fish from the Jacarepaguá Lagoon( Rio de Janeiro, Brazil) : ecological implication and human health risk. Toxicon, $2001,39(7): 1077-1085$.

[25] Mohamed ZA, Carmichael WW, Hussein AA et al. Estimation of microcystins in the freshwater fish Oreochromis niloticus in an Egyptian fish farm containing a Microcystis bloom. Environmental Toxicology, 2003,18(2) :137-141.

[26] Xie L, Xie P, Guo L et al. Organ distribution and bioaccumulation of Microcystins in freshwater fish at different trophic levels from the eutrophic lake Chaohu, China. Environmental Toxicology, 2005,20 (3) :293-300.

[27] Dewes LJ, Sandrini JZ, Monserrat JM et al. Biochemical and physiological responses after exposure to microcystins in the crab Chasmagnathus granulatus (Decapoda, Brachyura). Ecotoxicology and Environmental Safety, 2006,65(2):201-208.

[28] Chen J, Xie P. Microcystin accumulation in freshwater bivalves from Lake Taihu, China, and the potential risk to human consumption. Environmental Toxicology and Chemistry, 2007 ,26(5) : 1066-1073. 